\title{
COMPETITIVIDADE DO BRASIL NO MERCADO INTERNACIONAL DE AGLOMERADO ${ }^{1}$
}

\author{
Rommel Noce², Márcio Lopes da Silva ${ }^{3}$, Agostinho Lopes de Souza $^{3}$, Orlando Monteiro da Silva ${ }^{4}$, \\ Lourival Marin Mendes ${ }^{5}$, Rosa Maria Miranda Armond Carvalho² e Sebastião Renato Valverde ${ }^{3}$
}

\begin{abstract}
RESUMO - Este estudo objetivou caracterizar a estrutura do mercado internacional de aglomerado quanto à sua concentração e desigualdade, bem como decompor as variações nas exportações desse produto dos principais países participantes em efeito-crescimento do comércio mundial, efeito-destino e efeito-competitividade no período de 1998 a 2002. O nível de concentração e desigualdade favorece práticas anticompetitivas. O efeitocompetitividade, composto por aspectos endógenos, não favorece o aumento das exportações brasileiras.
\end{abstract}

Palavras-chave: Economia florestal, competitividade e aglomerado.

\section{BRAZIL'S COMPETIVITY IN THE INTERNATIONAL MARKET OF PARTICLEBOARD}

\begin{abstract}
This study aimed to characterize the structure of the international market of particleboard in relationship to its concentration and inequality and to decompose the variations in particleboard export in the major participant countries in terms of world trade growth effect, destination effect and competitiveness effect from 1998 to 2002. Concentration level and inequality favor anti-competitive practices and competitiveness effect, composed by endogenous aspects and market conditions, such as international agreements, do not favor Brazilian export growth.
\end{abstract}

Keywords: Forest economy, competitiveness and particleboard.

\section{INTRODUÇÃO}

O contexto da globalização promove maior interação entre as diferentes culturas e o acesso à informação em tempo real. Isso favorece a abertura econômica e a facilidade de transferência de investimentos na mesma proporção do aumento na velocidade de informação no mercado internacional.
A participação do setor florestal no mercado internacional se mostra relevante para a economia brasileira, por meio dos fluxos de capital, trabalho e produtos associados aos efeitos alocativos da atividade florestal e seu superávit (VALVERDE et al., 2003).

A crescente concentração de poder de mercado nas grandes organizações de alcance global, entretanto,

\footnotetext{
${ }^{1}$ Recebido em 26.07.2006 e aceito para publicação em 18.12.2007.

${ }^{2}$ Programa de Pós-Graduação em Ciência Florestal da Universidade Federal de Viçosa (UFV). E-mail : <rommelnoce@yahoo.com.br> e<rosamaria@homenet.com.br>.

${ }^{3}$ Departamento de Engenharia Florestal da UFV, Viçosa-MG. E-mail : <marlosil@ufv.br>.

${ }^{4}$ Departamento de Economia da UFV. E-mail : <odasilva@ufv.br>.

${ }^{5}$ Unidade Experimental de Produção de Painéis de Madeira da Universidade Federal de Lavras. E-mail : <lourival@ufla.br>.
} 
mostra-se como desafio para os países de economia emergente. O monopólio do comércio internacional e as práticas anticompetitivas nas redes de distribuição dificultam o acesso das nações em desenvolvimento aos mercados. Empresas e produtores tendem a ter o poder de negociação, a retenção de valores e a participação nas cadeias de valor reduzidas, e as firmas dominantes acabam por restringir a capacidade de inovar e diversificar e o acesso à tecnologia (UNITED NATIONS CONFERENCE ON TRADE AND DEVELOPMENTUNCTAD, 2004).

O Brasil apresenta excelentes condições, no curto prazo, para desenvolver a produção de painéis estruturais de madeira reconstituída (MENDES et al., 2003). A experiência no manejo de florestas de rápido crescimento, amplamente difundida e associada às condições edafoclimáticas, torna possível otimizar o uso dos recursos florestais.

O crescimento da produção de painéis de madeira, durante a década de 1990, consolidou a posição da indústria de aglomerados na economia brasileira, apresentando taxas de crescimento superiores às dos demais segmentos do setor florestal (TUOTO e MIYAKE, 2001).

Este estudo teve como objetivo caracterizar a estrutura do mercado internacional de aglomerado quanto às exportações no período de 1998 a 2002 e decompor o desempenho brasileiro e dos principais participantes do mercado internacional nas exportações de aglomerado em efeito-destino, crescimento de mercado e competitividade em dois períodos (1998 a 2000 e 2000 a 2002).

\section{MATERIAL E MÉTODOS}

Quanto à desigualdade e concentração das exportações, a estrutura do mercado internacional de aglomerado foi estudada por meio do Coeficiente de Gini (G) e da participação das quatro principais nações exportadoras (Canadá, Alemanha, Bélgica e Áustria) nos anos de 1998, 2000 e 2002.

A variação nas exportações das principais nações participantes no mercado internacional de aglomerado foi decomposta em efeito-crescimento do comércio mundial, efeito-destino e efeito-competitividade. Foram analisados os períodos de 1998/2000 e 2000/2002 para as exportações do Canadá, Alemanha, Bélgica, Áustria e Brasil, ao empregar uma adaptação do modelo "Constant Market Share” (CMS) (RICHARDSON, 1971). Foram consideradas competitivas as nações que aumentaram sua participação de mercado (GONÇALVES, 1987; HORTA, 1993; MEDEIROS e FONTES, 1994).

O Coeficiente de Gini (G) (Quadro 1) foi calculado pela equação 1, proposta por Nogimoto (1987):

$$
G=1-\frac{\sum_{i=1}^{n}\left(C_{i j}+C_{j}\right)}{n}
$$

sendo $\mathrm{n}=$ número de nações, $\mathrm{C}_{\mathrm{ij}}=$ participação acumulativa nas exportações em ordem crescente e $\mathrm{C}_{\mathrm{i}}=$ participação da empresa $\mathrm{i}$.

A classificação do mercado internacional foi realizada de acordo com Gregory (1987), quanto à concentração, conforme a participação dos quatro maiores exportadores: extremamente concentrado (75\%), altamente concentrado (50\% a $74 \%)$, moderadamente concentrado (25\% a $49 \%$ ) e relativamente pouco concentrado (24\%).

O método CMS é utilizado para analisar os fatores que exercem influência nas exportações de uma nação em um horizonte temporal. A taxa de crescimento das exportações foi decomposta em três efeitos, conforme proposto por Carvalho (2004): efeito-crescimento do comércio mundial (a expansão ou retração do volume de comércio global afeta diretamente as exportações das nações); efeito-destino (resulta da escolha de mercados mais aquecidos, com crescimento acima da média mundial, para direcionar as exportações); e efeitocompetitividade (determinado de forma residual, resulta de vários fatores, como preços relativos, mudanças tecnológicas, medidas de apoio ao setor exportador, melhoria de condições de financiamento e aumento da eficiência em “marketing”).

Quadro 1 - Interpretação do coeficiente de Gini Table 1 - Interpretation of the coefficient of Gini

\begin{tabular}{cc}
\hline Valor do Coeficiente de Gini & Desigualdade do Mercado \\
\hline $0,101-0,250$ & Nula a fraca \\
$0,251-0,500$ & Fraca a média \\
$0,501-0,700$ & Média a forte \\
$0,701-0,900$ & Forte a muito forte \\
$0,901-1,000$ & Muito forte a absoluta \\
\hline
\end{tabular}

Fonte: Carvalho, citado por Silva (2003). 
A variação nas exportações de aglomerado dos exportadores considerados e a contribuição de cada um dos componentes para o aumento ou decréscimo das exportações foram estudadas com a equação de Richardson (1971):

$\sum_{j}\left(V_{j}^{\prime}-V_{j}\right)=\sum_{j} r V_{j}+\sum_{j}\left(r_{j}-r\right) V_{j}+\sum_{j}\left(V_{j}^{\prime}-V_{j}-r_{j} V_{j}\right)$

sendo $\mathrm{V}_{\mathrm{j}}=$ valor das exportações do país em questão para o mercado j, no período $1 ; \mathrm{V}_{\mathrm{j}}{ }_{\mathrm{j}}=$ valor das exportações do país em questão para o mercado j, no período 2; $\mathrm{V}_{\mathrm{j}}{ }^{-}-\mathrm{V}_{\mathrm{j}}=$ crescimento efetivo do valor das exportações do país em questão para o mercado $j ; r_{j}=\frac{X m^{\prime}{ }_{j}}{X m_{j}}-1=$ taxa de crescimento percentual do valor das exportações mundiais para o mercado $j ; r=\frac{X m^{\prime}}{X m}-1=$ taxa de crescimento porcentual do valor das exportações mundiais; $\mathrm{Xm}_{\mathrm{j}}=$ valor das exportações mundiais para o mercado j, exceto as exportações do país em questão, no período 1; e $\mathrm{Xm}_{\mathrm{j}}{ }_{\mathrm{j}}=$ valor das exportações mundiais para o mercado j, exceto as exportações do país em questão, no período 2 .

De forma que os efeitos são determinados pelo efeito crescimento $=\sum_{j=1}^{n} r V_{j} ;$ efeito destino $=\sum_{j=1}^{n} r_{j} V_{j}-\sum_{j=1}^{n} r V_{j}$; e efeito competitividade $=\sum_{j=1}^{n} V_{j}^{\prime_{j}}-\sum_{j=1}^{n} V_{j}-\sum_{j=1}^{n} r_{j} V_{j}$.

Os dados utilizados foram obtidos na "Food and Agriculture Organization of the United Nations" - FAO (2005) e referem-se ao comércio bilateral das nações que participaram do mercado internacional de aglomerados, nos anos de 1998, 2000 e 2002. Os valores estão em milhares de dólares e discriminados por destino, de forma a ser possível operacionalizar os modelos adotados.

A forma como os dados foram organizados permitiu considerar na análise, em média, 93 países, sendo possível definir 87,97\% do destino das exportações das nações participantes no mercado internacional de aglomerado, de 1998 a 2000 e de 2000 a 2002. O porcentual não analisado foi observado nos dados como outros países, sem serem discriminados.

\section{RESULTADOS E DISCUSSÃO}

\subsection{Concentração e desigualdade do mercado internacional de aglomerado}

Os principais exportadores de aglomerado foram Canadá, Alemanha, Bélgica e Áustria, com destaque para o Canadá, que respondeu por 31,30\%, 51,80\% e $34,71 \%$ do total exportado nos anos de 1998, 2000 e 2002, respectivamente (Quadro 2).

A concentração foi alta com os quatro principais participantes, atingindo 60,18; 70,13; e 65,40\% do valor exportado em 1998, 2000 e 2002, tendo o Canadá 34,71\% do comércio de aglomerado no ano de 2002. O segundo exportador em importância, a Alemanha, participou com pouco mais de $13 \%$ nesse ano.

A desigualdade foi em nível mais alto, sendo de muito forte a absoluta, com o Coeficiente de Gini (G) de 0,91; 0,93; e 0,92 para os anos de 1998, 2000 e 2002, respectivamente, com ponto máximo de desigualdade no ano 2000.

\subsection{Análise CMS do mercado internacional de aglomerado}

No período de 1998 a 2000, as exportações do Canadá aumentaram em $174,50 \%$. O efeito-crescimento do comércio mundial foi capaz de aumentar as exportações canadenses em 9,49\%. O efeito-destino reduziu as exportações em 40,73\%. Já o efeito-competitividade, que combina um grupo de aspectos endógenos, foi capaz de aumentar as exportações em 205,74\% (Quadro 3).

Quadro 2 - Participação no mercado internacional das principais nações exportadoras de aglomerado - 1998-2002 (US\$1.000,00) Table 2 - International market participation by the major particleboard export nations-1998-2002 (US\$1.000,00)

\begin{tabular}{lcccccc}
\hline \multicolumn{1}{c}{ País } & 1998 & $\%$ & 2000 & $\%$ & 2002 & $\%$ \\
\hline Canadá & $1.291 .573,00$ & 31,30 & $3.545 .437,00$ & 51,80 & $1.331 .223,00$ & 34,71 \\
Alemanha & $511.926,00$ & 12,40 & $525.206,00$ & 7,67 & $508.971,00$ & 13,27 \\
Bélgica & $359.000,00$ & 8,70 & $377.367,00$ & 5,51 & $325.212,00$ & 8,48 \\
Áustria & $320.702,00$ & 7,77 & $352.192,00$ & 5,14 & $342.468,00$ & 8,93 \\
$\mathrm{~N}^{\circ}$ Participantes & & 87 & & 97 & 86 \\
$\%$ 4 principais & & 60,18 & & 70,13 & & 65,40 \\
\hline Total & $4.125 .861,00$ & & & & $3.834 .470,00$ \\
\hline
\end{tabular}

Fonte: FAO (2005). 
Quadro 3 - Resultado de "Constant Market Share” do mercado internacional de aglomerado - 1998-2000 Table 3 - Result of Constant Market Share of the international particleboard market - 1998-2000

\begin{tabular}{|c|c|c|c|c|c|c|c|c|}
\hline \multirow{3}{*}{ Nações } & & & \multicolumn{6}{|c|}{ Efeitos } \\
\hline & \multicolumn{2}{|c|}{ Variação (\%) } & \multicolumn{2}{|c|}{ Crescimento Comércio Mundial (\%) } & \multicolumn{2}{|c|}{ Destino (\%) } & \multicolumn{2}{|c|}{ Competitividade (\%) } \\
\hline & $\mathrm{P} 1 *$ & $\mathrm{P} 2 * *$ & $\mathrm{P} 1 *$ & $\mathrm{P} 2 * *$ & $\mathrm{P} 1 *$ & $\mathrm{P} 2 * *$ & $\mathrm{P} 1 *$ & $\mathrm{P} 2 * *$ \\
\hline Canadá & 174,50 & $-62,45$ & 9,49 & $-18,42$ & $-40,73$ & $-11,54$ & 205,74 & $-32,49$ \\
\hline Alemanha & 2,45 & $-2,40$ & 61,04 & $-46,58$ & $-35,92$ & 26,73 & $-22,67$ & 17,45 \\
\hline Bélgica & 5,66 & $-8,24$ & 68,15 & $-43,90$ & $-48,18$ & $-1,22$ & $-14,31$ & 36,88 \\
\hline Áustria & 9,84 & $-7,65$ & 65,44 & $-44,27$ & $-63,30$ & 10,98 & 7,71 & 25,63 \\
\hline Brasil & $-1,31$ & $-9,94$ & 61,01 & $-42,38$ & 2,29 & 51,04 & $-64,61$ & $-18,60$ \\
\hline
\end{tabular}

* Período: 1998 a 2000; ** Período: 2000 a 2002.

No período de 2000 a 2002, o Canadá apresentou redução de 62,45\% nas exportações. Em função do efeitocrescimento do comércio mundial, as exportações canadenses caíram $18,42 \%$, e o efeito-destino se reduziu em $11,54 \%$. O efeito-competitividade, que no período anterior foi responsável pelo bom desempenho, neste reduziu as exportações em 32,49\% (Quadro 3).

AAlemanha apresentou aumento de 2,45\% em suas exportações de 1998 a 2000. O efeito-crescimento do comércio mundial foi capaz de aumentar as exportações em $61,04 \%$. Porém, o efeito-destino foi capaz de reduzir as exportações em $35,92 \%$, enquanto o efeitocompetitividade ainda agiu de forma a reduzir as exportações em 22,67\% (Quadro 3).

No segundo período, a Alemanha apresentou desempenho negativo, e suas exportações caíram 2,40\%. O efeito-crescimento do comércio mundial representou redução de $46,58 \%$ nas exportações. O efeito-destino apresentou contribuição da ordem de $26,73 \%$ para o aumento das exportações, que, juntamente com a contribuição de 17,45\% do efeito-competitividade, foram absorvidas pela forte redução imposta pelo efeitocrescimento do comércio mundial (Quadro 3).

A Bélgica apresentou aumento de 5,66\% em suas exportações no período de 1998-2000. O efeitocrescimento do comércio mundial favoreceu o aumento das exportações em 68,15\%, enquanto o efeito-destino e a competitividade desfavoreceram o aumento das exportações em 48,18\% e 14,31\%, respectivamente (Quadro 3).

Notou-se redução nas exportações da Bélgica em $8,24 \%$. Os efeitos-crescimento do comércio mundial e destino que desfavoreceram as exportações em 43,90\% e $1,22 \%$, respectivamente, anularam o efeito- competitividade que favoreceu o incremento das exportações em 36,88\% (Quadro 3).

A Áustria apresentou aumento de 9,84\% nas suas exportações, no período de 1998 a 2000 . Isso foi resultado do efeito-crescimento do comércio mundial favorável em 65,44\% ao aumento das exportações, deduzido do efeito-destino desfavorável de 63,30\% e acrescido do efeito competitividade de 7,71\% (Quadro 3).

No período de 2000 a 2002, a Áustria apresentou redução de 7,65\% em suas exportações, em função do efeito de crescimento do comércio mundial, que reduziu suas exportações em 44,27\%, absorvendo os efeitos favoráveis de destino e a competitividade de 10,98\% e 25,66\%, respectivamente (Quadro 3).

O Brasil apresentou redução nas exportações de $1,31 \%$ no período de 1998 a 2000 . O efeito de crescimento do comércio mundial de $61,01 \%$, aliado ao efeito-destino de 2,29\% a favor das exportações, não foi suficiente para suportar o efeito-competitividade, que desfavoreceu as exportações em 64,61\% (Quadro 3).

No período 2000 a 2002, as exportações brasileiras se reduziram em 9,94\%, como resultado da combinação do efeito-crescimento do comércio mundial e efeitocompetitividade desfavoráveis em 42,38\% e 18,60\%, respectivamente, que superaram o efeito-destino de 51,04\%, favorável ao crescimento das exportações (Quadro 3).

O mercado internacional de aglomerado esteve concentrado e desigual, sendo o contexto agravado pela hegemonia canadense. O Canadá respondeu por $82,91 \%$ do significativo aumento de $65,88 \%$ nas exportações mundiais de 1998 a 2000 . O total de 87,15\% da variação das exportações foi em função do incremento da demanda norte-americana, o que evidencia como o mercado é restrito. 
O cenário do mercado ainda foi composto pela participação canadense em 98,02\% das exportações, tendo como destino os Estados Unidos da América (EUA). Assim, o Canadá deteve grande parte do aumento de mercado observado no período, praticamente concentrado no destino aos EUA. Todas as nações vivenciaram significativo efeito de crescimento do comércio mundial favorável às exportações, porém também significativo foi o efeito-destino desfavorável, imposto à maioria das nações, uma vez que o mercado "mais aquecido”, que seria o dos EUA, foi absorvido, quase em sua totalidade, pelas exportações canadenses. $\mathrm{O}$ Brasil apresentou composição atípica, em comparação com as outras nações que não concentraram suas exportações no mercado norte-americano, à exceção do Canadá, com suas exportações direcionadas, em grande parte, para o mercado norte-americano, tendo apresentado efeito-destino positivo, mas com efeitocompetitividade desfavorável mais intenso.

A indústria brasileira de aglomerados apresentou como aspectos limitantes o fato de o transporte de madeira não ocorrer de forma otimizada e, principalmente, a composição de custo da produção em que o adesivo representa custo semelhante ao da madeira (SOUSA, 2000). No Brasil, o custo do adesivo é bem mais elevado que em países como o Canadá e os EUA, sendo produzido por poucas empresas multinacionais. No segundo biênio ocorreu o contrário; de forma análoga, o Canadá reduziu sua exportação de forma tão abrupta quanto a aumentou no período anterior, impondo aos participantes do mercado internacional forte-efeito de crescimento do comércio mundial desfavorável às exportações. O Brasil, apesar de ter mostrado efeito-destino favorável, apresentou mais uma vez efeito-competitividade desfavorável, menos intenso que o observado no período de 1998/2002, em função dos avanços tecnológicos na indústria de aglomerados, porém suficiente para reduzir as exportações brasileiras.

O atentado de 11 de setembro de 2001 ao "World Trade Center” agravou os efeitos da desaceleração da economia mundial originada nos EUA, reduzindo o intercâmbio comercial em nível global. O que certamente, contribuiu para que as principais nações exportadoras de aglomerado apresentassem o efeito-crescimento do comércio mundial desfavorável ao aumento das exportações no período de 2000 a 2002.
O nível de concentração e desigualdade no mercado internacional de aglomerado é semelhante ao observado em outros produtos, como a madeira serrada (NOCE et al., 2005).

Os resultados da decomposição do desempenho das exportações brasileiras, por sua vez, contrastam com os observados em estudos anteriores que enfocavam produtos florestais de menor valor agregado. Estes apresentaram relativa competitividade apoiada prioritariamente, em aspectos endógenos, a exemplo da madeira serrada (NOCE et al., 2003) e da celulose (MEDEIROS e FONTES, 1994). Da mesma forma, produtos de maior valor agregado como móveis, nos quais os painéis são utilizados como matérias-primas, já se mostraram competitivos em análises anteriores em função do efeito-competitividade (COELHO e BERGER, 2004).

Nota-se que o potencial do Brasil é significativo, denotado pela competitividade do Brasil em produtos que são utilizados como insumos no processo produtivo de painéis, bem como em outros em que os painéis representam os insumos. Destaca-se que a magnitude do efeito desfavorável foi minimizada pela presente evolução da indústria de aglomerados.

\section{CONCLUSÃO}

Para as condições em que foi desenvolvido este estudo, conclui-se que:

A estrutura do mercado internacional de aglomerado se caracterizou pela concentração e desigualdade, o que favoreceu o uso de práticas anticompetitivas.

Embora o Brasil tenha apresentado resultados que indicavam que os aspectos endógenos desfavoreciam as exportações, a magnitude desses efeitos diminuiu de forma significativa, o que demonstrou a evolução da indústria de aglomerados do biênio de 1998/2000 para o de 2000/2002.

A hegemonia canadense no mercado internacional de aglomerado exerceu forte influência nos resultados gerais do mercado.

O uso de tratados políticos e comerciais que compõem, junto com vários aspectos endógenos, o efeito-competitividade reduziu os benefícios que poderiam ser obtidos com vantagens comparativas brasileiras e o esforço estratégico da indústria no mercado de aglomerados.

R. Árvore, Viçosa-MG, v.32, n.1, p.113-118, 2008 
Este estudo permitiu equacionar a desigualdade do mercado internacional de aglomerado, assim como a hegemonia do Canadá, contribuindo para a visibilidade do mercado.

\section{REFERÊNCIAS}

CARVALHO, F. M. A. Método "Constant Market Share” (CMS). In: SANTOS, M.L.; VIEIRA, W. C. Métodos quantitativos em economia. Viçosa, MG: Universidade Federal de Viçosa, 2004. p.225-241.

COELHO, M. R. F.; BERGER, R. Competitividade das exportações brasileiras de móveis no mercado internacional: uma análise segundo a visão desempenho. Revista da FAE, v.7, n.1, p.51-65, 2004.

FOOD AND AGRICULTURE ORGANIZATION OF THE UNITED NATIONS - FAO. Forestry data bilateral trade matrices. Disponivel em: $<$ http://faostat.fao.org/faostat/forestry/jsp/fytf_q.jsp?language $=E N \&$ version $=$ ext $\&$ hasbulk $=>$ Acesso em: 15 fev. de 2005.

GONÇALVES, R. Competitividade internacional, vantagem comparativa e empresas multinacionais: o caso das exportações brasileiras de manufaturados. Pesquisa e Planejamento Econômico, v.17, n.2, p.411-436, 1987.

GREGORY, G. R. Resource economics for foresters. New York: John Wiley \& Sons, 1987. 477p.

HORTA, M. H. T. T. Fontes de crescimento das exportações brasileiras na década de 70 .

Pesquisa e Planejamento Econômico, v.13, n.2, p.507-542, 1993.

MEDEIROS, V. X.; FONTES, R. M.

Competitividade das exportações brasileiras de celulose no mercado internacional. Revista Brasileira de Economia e Sociologia Rural, v.32, n.2, p.105-121, 1994.

MENDES L. M.; ALBUQUERQUE, C. E. C.; IWAKIRI, S. A indústria brasileira de painéis de madeira. Revista da Madeira, n.71, p.12-20, 2003.

R. Árvore, Viçosa-MG, v.32, n.1, p.113-118, 2008
NOCE, R. et al. O desempenho do Brasil nas exportações de madeira serrada. Revista Árvore, v.27, n.5, p.695-700, 2003.

NOCE, R. et al. Concentração das exportações no mercado internacional de madeira serrada.

Revista Árvore, v.29, n.3, p.431-437, 2005.

NOGIMOTO, T. Obstáculos à mecanização da agricultura brasileira. 1987. 354 f. Tese (Doutorado em Economia) - Universidade de São Paulo, São Paulo, 1987.

RICHARDSON, D. Constant-market-shares analysis of export growth. Journal of International Economics, v.1, n.1, p.227-239, 1971.

SILVA, Z. A. G. P. G. Análise econômica da concentração no uso de madeira tropical pelo setor de marcenarias de Rio Branco, Estado do Acre, 1996. Scientia Forestalis, n.64, p.48-58, 2003.

SOUSA, R. A. T. M. Análise do fluxo de transporte rodoviário de toras curtas de eucalipto para algumas indústrias de celulose e de chapas de composição no estado de São Paulo. 2000. 115f. Tese (Doutorado em Recursos Florestais) - Escola Superior de Agricultura Luiz de Queiroz, Piracicaba, 2000.

TUOTO, M.; MIYAKE, N. A indústria de painéis de madeira supera as expectativas.

Informativo STCP, n.5, p.21-22, 2001.

\section{UNITED NATIONS CONFERENCE ON TRADE} AND DEVELOPMENT - UNCTAD. Assegurando ganhos de desenvolvimento a partir do sistema comercial internacional e das negociações de comércio. In: REUNIÃO QUADRIANUAL DA CONFERÊNCIA DAS NAÇÕES UNIDAS PARAO COMÉRCIO E O DESENVOLVIMENTO, 11., 2004, São Paulo. Anais... São Paulo: 20p. Disponível em: < http://www.unctad.org/pt/docs/ td397_pt.pdf>. Acesso em: 15 mai. 2005.

VALVERDE, S. R. et al. Evolução da participação do setor florestal na economia brasileira. In: CONGRESSO FLORESTAL BRASILEIRO, 8., 2003, São Paulo. Anais... São Paulo: SBS/SBEF, 2003. v.2. CD-ROM. 